\title{
Bubble Nasal Continuous Positive Airway Pressure (bCPAP) versus Control in Neonates with Respiratory Distress
}

\author{
Tehreem Fatima, Muhammad Haroon Hamid, Abdul Ahad Jamshaid and Areeba Wasim \\ Department of Paediatric Medicine, King Edward Medical University, Lahore, Pakistan
}

\begin{abstract}
Objective: To compare the effectiveness of bubble continuous positive airway pressure (bCPAP) and oxygen inhalation via nasal cannula in neonates presenting with respiratory distress, using Silverman Anderson Retraction Score (SARS).

Study Design: Randomised clinical trial.

Place and Duration of Study: Department of Paediatrics, Unit-1, KEMU/Mayo Hospital, Lahore, Pakistan, from April 2017 to June 2018.

Methodology: A total of 120 neonates fulfilling inclusion and exclusion criteria were enrolled and were randomly allocated in two groups: Group A and Group B. In group A, neonates were given bCPAP for respiratory support, while neonates in group B were given nasal oxygen as control group. Neonates in both groups were followed for 48 hours. The effectiveness was determined by the reduction in SARS, up to or less than score 3, at the end of a 48-hour period. Data were collected and analysed by SPSS version 20.0. P-value $\leq 0.05$ was taken as significant.

Results: In Group A, effectiveness was found to be $93.3 \%$, and in Group B effectiveness was $71.7 \%(p=0.003)$. Median reduction in SARS from 00 to 48 hours, in group A (bCPAP) was $4(4-5)$ while in group B (control), it was $3(2-3)$; statistically significant $(p<0.001)$.

Conclusion: Bubble CPAP was more effective than nasal oxygen alone, in treatment of respiratory distress among neonates. This study suggested that bCPAP should be used more frequently in NICUs of Pakistan to reduce burden of neonatal morbidity due to respiratory distress.
\end{abstract}

Key Words: Bubble CPAP, Respiratory distress, Neonates, Silverman Anderson Retraction Score.

How to cite this article: Fatima T, Hamid MH, Jamshaid AA, Wasim A. Bubble Nasal Continuous Positive Airway Pressure (bCPAP) versus Control in Neonates with Respiratory Distress. J Coll Physicians Surg Pak 2020; 30(08):805-809.

\section{INTRODUCTION}

Neonatal mortality comprises of $41 \%$ of under-five mortality rate. ${ }^{1}$ Four million neonates die every year all over the world and $98 \%$ of these deaths are solely accounted for by the developing countries. ${ }^{2}$ Respiratory ailments are major contributor to the neonatal mortality and one-fifth of the neonatal deaths in developed world are caused by respiratory diseases alone., Bubble CPAP is one of the major advancements developed for the management of respiratory distress ${ }^{1,5}$ According to a review article, use of continuous positive airway pressure has increased by almost $5 \%$ over the last decade in US. ${ }^{6}$

Correspondence to: Dr. Tehreem Fatima, Department of Paediatric Medicine, King Edward Medical University,

Lahore, Pakistan

E-mail: tehreem fatima_14@hotmail.com

Received: April 16, 2020; Revised: July 18, 2020;

Accepted: July 22, 2020

DOI: https://doi.org/10.29271/jcpsp.2020.08.805
However, in developing countries, there is a need for accessible and cost-effective methods for providing ventilator assistance to neonates with respiratory distress. ${ }^{1}$

Bubble CPAP (bCPAP) is a non-invasive technique used successfully in developed countries as well as resourcelimited countries including Malawi, India and Pakistan. ${ }^{1,3,4,7}$ Currently, multiple studies for comparing effectiveness of nasal oxygen therapy and bCPAP are being conducted and it is speculated that bCPAP use will increase survival rates up to $70 \%{ }^{5}$

A few studies conducted specially in preterm babies have shown that the use of CPAP, as an early intervention, has resulted in decreased incidence of chronic lung disease as well as of non-respiratory co-morbidities. ${ }^{8}$

This technique makes use of a basic principle of providing positive airway pressure during both inspiration and expiration, helps maintaining lung recruitment, increases FRC, decreases ventilation-perfusion mismatch and decreases the work of breathing. ${ }^{9}$ 
Table I: Demographic characteristics of study population $(n=120)$

\begin{tabular}{|c|c|c|c|c|}
\hline & $\begin{array}{c}\text { Group A (bCPAP) } \\
n=60\end{array}$ & $\begin{array}{l}\text { Group B (nasal oxygen) } \\
\qquad n=60\end{array}$ & $\begin{array}{c}\text { Total } \\
n=120\end{array}$ & p-value \\
\hline $\begin{array}{l}\text { Gender } \\
\text { Male } \\
\text { Female }\end{array}$ & $\begin{array}{l}32(53.3 \%) \\
28(46.7 \%)\end{array}$ & $\begin{array}{l}33(55 \%) \\
27(45 \%)\end{array}$ & $\begin{array}{l}65(54.2 \%) \\
55(45.8 \%)\end{array}$ & 0.855 \\
\hline $\begin{array}{l}\text { Gestational age (in weeks) } \\
\text { Median (IQR) } \\
\text { Preterm (32w-37w) } \\
\text { Term ( } \geq 37 w)\end{array}$ & $\begin{array}{c}38(36-39) \\
16(26.7 \%) \\
44(73.3 \%)\end{array}$ & $\begin{array}{l}38(37-39) \\
13(21.7 \%) \\
47(78.3 \%)\end{array}$ & $\begin{array}{l}38(37-39) \\
29(24.2 \%) \\
91(75.8 \%)\end{array}$ & $\begin{array}{l}0.473 \\
0.522\end{array}$ \\
\hline $\begin{array}{l}\text { Patient's age at admission (in days) } \\
\text { Median (IQR) } \\
0-7 \text { days } \\
\text { 7-28 days }\end{array}$ & $\begin{array}{c}1(1-8) \\
44(73.3 \%) \\
16(26.7 \%)\end{array}$ & $\begin{array}{l}1(1-6.75) \\
46(76.7 \%) \\
14(23.3 \%)\end{array}$ & $\begin{array}{c}1(1-7.75) \\
90(75 \%) \\
30(25 \%)\end{array}$ & $\begin{array}{l}0.984 \\
0.673\end{array}$ \\
\hline $\begin{array}{l}\text { Weight (in } \mathrm{Kg}) \\
\text { Median (IQR) } \\
\text { LBW }(1.5 \mathrm{Kg}-2.5 \mathrm{Kg}) \\
\text { Normal wt }(\geq 2.5 \mathrm{Kg})\end{array}$ & $\begin{array}{c}2.8(2.125-3) \\
19(31.7 \%) \\
41(68.3 \%)\end{array}$ & $\begin{array}{l}2.7(2.2-3) \\
23(38.3 \%) \\
37(61.7 \%)\end{array}$ & $\begin{array}{c}2.7(2.2-3) \\
42(35 \%) \\
78(65 \%)\end{array}$ & $\begin{array}{l}0.829 \\
0.444\end{array}$ \\
\hline
\end{tabular}

Table II: Comparison of effectiveness between both groups $(n=120)$.

\begin{tabular}{|c|c|c|c|c|}
\hline & Group A (bCPAP) & Group B (nasal oxygen) & Total & p-value \\
\hline $\begin{array}{l}\text { Effectiveness } \\
\text { Yes } \\
\text { No }\end{array}$ & $\begin{array}{c}56(93.3 \%) \\
4(6.7 \%)\end{array}$ & $\begin{array}{l}43(71.7 \%) \\
17(28.3 \%)\end{array}$ & $\begin{array}{l}99(82.5 \%) \\
21(17.5 \%)\end{array}$ & $0.003^{*}$ \\
\hline SARS at 00 hours Median (IQR) & $6(6-7)$ & $6(5-6)$ & $6(5-7)$ & $<0.001^{* *}$ \\
\hline SARS at 48 hours Median (IQR) & $2(2-3)$ & $3(2-3)$ & $3(2-3$ & $<0.001 * *$ \\
\hline$\triangle$ SARS 00-48 H *** Median (IQR) & $4(4-5)$ & $3(2-3)$ & $4(2.5-4)$ & $<0.001 * *$ \\
\hline
\end{tabular}

Table III: Distribution of patients according to severity of SAR score ( $\mathbf{n}=120$ ).

\begin{tabular}{|c|c|c|c|c|c|c|c|c|c|c|c|}
\hline \multirow{3}{*}{$\begin{array}{l}\text { No. of patients } \\
\text { (percentage) }\end{array}$} & \multicolumn{11}{|c|}{ Silverman Anderson Retraction Score } \\
\hline & \multicolumn{4}{|c|}{$\begin{array}{c}0-3 \\
\text { (Mild respiratory distress) }\end{array}$} & \multicolumn{3}{|c|}{$\begin{array}{c}\text { (Moderate respiratory distress) } \\
\text { (Mod }\end{array}$} & \multicolumn{4}{|c|}{$\begin{array}{c}\text { 7-10 } \\
\begin{array}{c}\text { (Severe respiratory distress-implies impending } \\
\text { respiratory failure) }\end{array}\end{array}$} \\
\hline & 0 & 1 & 2 & 3 & 4 & 5 & 6 & 7 & 8 & 9 & 10 \\
\hline \multicolumn{12}{|l|}{ At 00 hours } \\
\hline Group A ( $n)$ & - & - & - & - & $1(1.7)$ & $5(8.3)$ & $26(43.3)$ & $18(30)$ & $10(16.7)$ & - & - \\
\hline Group B $(n)$ & - & - & - & - & $6(10)$ & $23(38.3)$ & $22(36.7)$ & $7(11.7)$ & $2(3.3)$ & - & - \\
\hline Total $(n)$ & - & - & - & - & $7(5.8)$ & $28(23.3)$ & $48(40)$ & $25(20.8)$ & $12(10)$ & - & - \\
\hline \multicolumn{12}{|l|}{ At 48 hours } \\
\hline Group A (n) & $5(8.5)$ & 7 (11.9) & $25(42.4)$ & $19(32.2)$ & $3(5.1)$ & 0 & - & - & - & - & - \\
\hline Group B (n) & $1(1.7)$ & $2(3.4)$ & $14(24.1)$ & $28(48.3)$ & $11(19)$ & $2(3.4)$ & - & - & - & - & - \\
\hline Total $(n)$ & $6(5.1)$ & $9(7.7)$ & $39(33.3)$ & $47(40.2$ & $14(12)$ & $2(1.7)$ & - & - & - & - & - \\
\hline \multicolumn{12}{|c|}{$\triangle$ SARS (Change in SAR Score from 00 to 48 hours) } \\
\hline & 0 & 1 & 2 & 3 & 4 & 5 & 6 & 7 & 8 & 9 & 10 \\
\hline Group A $(n)$ & - & 0 & $1(1.7)$ & $6(10.2)$ & $28(47.5)$ & $20(33.9)$ & $3(5.1)$ & $1(1.7)$ & - & - & - \\
\hline Group B ( $n)$ & - & $4(6.9)$ & $24(41.4)$ & $20(34.5)$ & $8(13.8)$ & $2(3.4)$ & 0 & 0 & - & - & - \\
\hline Total $(n)$ & - & $4(3.4)$ & $25(21.4)$ & $26(22.2)$ & $36(30.8)$ & $22(18.8)$ & $3(2.6)$ & $1(0.9)$ & - & - & - \\
\hline
\end{tabular}

Many home-made, low-budget designs have been used keeping in mind the basic combination of (i) an oxygen source, (ii) pressure generating system and (iii) a patient interface. ${ }^{7,9}$

In a randomised trial, 71\% neonates in DCPAP group survived compared to $44 \%$ neonates in nasal oxygen group during the course of study $(p=0.006) .{ }^{4}$ It was concluded that the effectiveness of bCPAP was $27 \%$ in terms of survival. ${ }^{4}$
Improvement in severity of respiratory distress after implementing bCPAP could also be measured in terms of reduction in Silverman Anderson Retraction Score (SARS). ${ }^{3,10}$ According to a study conducted in Uganda, the average SARS was $7.4 \pm 1.3$ before starting bCPAP, $5.2 \pm 2.3$ after $2-4$ hours, $4.9 \pm 2.7$ after $12-24$ hours, and $3.5 \pm 1.9$ at the end of study. ${ }^{10}$

Through literature review, it was noticed that bCPAP was 
preferred as compared to conventional nasal oxygen and also resulted in significant reduction in need for mechanical ventilation. However, very few evidences have been found in literature regarding use of bCPAP in NICUs across Pakistan and its effectiveness. ${ }^{11}$ This study will be an addition to the native data regarding effectiveness of bCPAP; not only in preterm neonates, but in term neonates as well. ${ }^{12}$

The objective of this study was to compare the effectiveness of bubble continuous positive airway pressure (bCPAP) and oxygen inhalation via nasal cannula in neonates presenting with respiratory distress, using Silverman Anderson Retraction Score (SARS).

\section{METHODOLOGY}

Sample size of 120 neonates was calculated with $95 \%$ confidence of interval and $80 \%$ power of test using WHO calculator. After approval from Institutional Review Board of King Edward Medical University/Mayo Hospital Lahore (Ref No. 126/RC/KEMU Dated:05/10/2016), neonates fulfilling inclusion and exclusion criteria were enrolled in the study from the neonatal section of Paediatric Medicine Department, KEMU/Mayo Hospital, Lahore, from April 2017 to June 2018. They were randomly allocated in two groups by using lottery method. Written informed consent was obtained from parents. Demographics (name, age, gestational age at birth, birth weight) were recorded. The inclusion criteria included neonates with gestational ages $\geq 32$ weeks, having respiratory distress (as per operational definition - respiratory rate $>60$ /minutes plus any of the following features: grunting, subcostal/intercostal retractions, nasal flaring, inability to maintain spO2 $>90 \%$ at room air) and having Silverman Anderson Retraction Score $\geq 4$. The exclusion criteria included neonates having gestational age less than 32 weeks and birth weight less than $1.5 \mathrm{Kgs}$. Neonates having congenital malformations, air leak syndromes, hypoxic ischemic encephalopathy and those developing apnea or requiring mechanical ventilation at the time of admission were also not included.

In group A, bCPAP was applied to neonates; while neonates in group $B$, were given nasal oxygen as control. The bCPAP was made using an oxygen flow meter as the oxygen source. This inspiratory limb containing oxygen from the flow meter was connected to humidifier and tubing from humidifier was connected to short binasal prongs, which were applied to neonate with the help of adhesive bandage on both cheeks. It was ensured that binasal prongs make appropriate seal. An orogastric tube was placed for gastric decompression. A $1000 \mathrm{ml}$ bottle was filled with sterile water and marks were made on it at $1 \mathrm{~cm}$ distance, with ' 10 ' marked at base and ' 0 ' marked at the water interface.

The expiratory limb from the nasal prongs was connected to tubing that was dipped in water up to the desired level to provide positive end expiratory pressure. Pressure was varied by varying the depth of the dipped end of tubing.
In nasal oxygen group, oxygen was delivered via a nasal cannula from a wall oxygen source. The oxygen was delivered between 1 to $6 \mathrm{~L} / \mathrm{min}$ and the rate was varied via a flow regulator. Neonates in both groups were followed-up for 48 hours. Silverman Anderson Retraction Score (SARS) was recorded at 0 and 48 hours $^{13}$. It consists of five components: chest retractions, retraction of the lower intercostal muscles, xiphoid retractions, flaring of nares with inhalation and grunting on exhalation. Each of the five factors is graded 0,1 and 2 . The sum of these factors yields the total score; minimum score is ' 0 ' and maximum score is ' 10 '. The higher the score, the greater is the severity of respiratory distress. So the severity of respiratory distress can be graded according to the SAR score as mild (score 0-3), moderate (score 4-6) and severe (score 6-10). A score of $\geq 6$ implies impending respiratory failure and a need to escalate the respiratory support. ${ }^{14}$

Effectiveness was recorded as 'positive' in case of reduction in SARS score $\leq 3$. A cut-off of score ' 3 ' was taken. So if the score of 3 or less than 3 was achieved with bCPAP or with nasal oxygen after 48 hours of intervention, the intervention was considered to be effective.

The data was collected and analysed by SPSS v20.0. Normality test, i.e. Shapiro-Wilk test was used to assess the normality of quantitative variables. Quantitative variables were presented as Median (IQR). SAR score of both groups was compared using Mann-Whitney U-test. Qualitative variables were presented as frequency and percentages. Both groups were compared using Chi-square/Fisher's exact test. P-value $\leq 0.05$ was considered as significant. Median reduction in SARS in both groups and their difference was also calculated. Data were stratified for gender, gestational age, birth weight and age at admission.

\section{RESULTS}

A total of 120 neonates were enrolled in this study - 60 in each, Group A (bCPAP) and Group B (Control). In Group A, 32 $(53.3 \%)$ neonates were males and $28(46.7 \%)$ neonates were females. Whereas, in Group B, 33 (55\%) neonates were males and 27 (45\%) neonates were females. (Table I)

Effectiveness was compared between the groups by using Silverman Anderson Retraction Score (SARS). ${ }^{13}$ In Group A, 56 out of 60 neonates (93.3\%) achieved a score of $\leq 3$; and in Group B, 43 out of 60 neonates (71.7\%) achieved a score of $\leq 3$, with a $p$-value of 0.003 that was significant. (Table II)

Median reduction of SARS score in both the groups (bCPAP and control group) was calculated using Mann-Whitney Utest for each group separately. Median reduction in SARS in Group A (bCPAP) was 4 (4 - 5), while in Group B (control) it was $3(2-3, p<0.001)$.

Patients in Group A (bCPAP) included more number of patients with higher SAR score, as compared to Group B (nasal oxygen), at the time of commencement of study (00 hours), as shown in Table III. Whereas, more number of 
patients achieved a lower SAR score in Group A at the end of '48 hours' as compared to those in Group B. Which means that the patients in Group A, had a greater change in SAR score from 00 to 48 hours, which was termed as "delta $\Delta$ SARS", as compared to patients in Group B. So the reduction in severity of respiratory distress was clearly more in Group A as compared to Group B; and this comparison was also clinically and statistically significant.

Demographical characteristics of the study population were comparable including the gestational ages, gender, day of life and weight at admission (Table I). Median gestational age in group A was 38 (36 - 39) weeks and in Group B was 38 (37 39) weeks. Patient data were also stratified as preterm (gestational age 32-37weeks) and term neonates ( $\geq 37$ weeks). Median birth weight at admission was $2.8(2.125$ - 3) $\mathrm{Kgs}$ in Group A and 2.7 (2.2 - 3) Kgs in Group B, the difference being insignificant between the groups. Patients were also stratified as low birth weight - LBW (weight $<2.5 \mathrm{Kg}$ ) and normal birth weight (weight $\geq 2.5 \mathrm{Kg}$ ). Median age at presentation to hospital in group A was 1 ( 1 - 8) days and in group B it was 1 (1 - 6.75) days (Table I).

In Group A, one neonate out of 60 (1.7\%) had to be shifted to mechanical ventilation because of persistent hypoxemia. While in Group B, 5 out of 60 (8.3\%) neonates had to be shifted to bubble CPAP because of persistent hypoxemia with simple nasal cannula in first 24 hours of enrolment. These patients showed improvement in SARS score afterwards and maintained oxygen saturation on bCPAP. Also in group B, 2 neonates required mechanical ventilation; and 1 of these patients expired.

\section{DISCUSSION}

Respiratory distress is a common problem faced in neonatal ICUs. Various scoring systems are in use in various paediatric setups to assess the severity of respiratory illness. One such score is Silverman Anderson Retraction Score, which was used in this study to assess the effectiveness of our device (bCPAP). ${ }^{13}$ The lower is the score achieved; the lower will be the severity. As the inclusion criteria included neonates $>32$ weeks of gestation so both term and pre-term neonates were included in the study. However the neonates below 32 weeks of gestation were not included in the study because of increased risk of co-morbidities.

Bubble CPAP is a simple device, which can easily be used by all health care professionals including the nursing staff. ${ }^{15}$ No technical difficulty was faced during its use. Its ease of application made it useful. The inspiratory limb of the bCPAP was attached to the oxygen flow meter easily available in ward and rate of oxygen flow adjusted with the flow regulator. Other equipment utilised in this device was also easily available in the NICU.

In this study, the effectiveness in the Group A (bCPAP) was 56/60 (93.3\%) and in Group B (Control) was 43/60 (71.7\%). These results seem to be similar to those achieved by another trial done to study the effectiveness of bCPAP. ${ }^{4}$ The primary outcome in this study was the improvement in severity of respiratory illness, and not the overall reduction in mortality or cost- effectiveness. The modality of CPAP has significantly reduced the burden of morbidity due to respiratory diseases not only in neonates but also older children, as depicted by various studies in developing countries. ${ }^{16}$ This study has added to the native data showing significant effectiveness of bCPAP.

Equipment design was slightly modified due to non-availability of air/oxygen blenders and pre-determined amount of $\mathrm{FiO}_{2}$ was not administered, these were considered as few of the limitations of this study. There are very few side effects of bubble CPAP; complications like the nasal septum and bridge injury, facial puffiness, abdominal distension and rarely pulmonary haemorrhage, have been reported in literature. ${ }^{17-19}$ But luckily, none of our patients developed any serious complications. This study doesn't show any improvement in chance of survival or decreased rate of requirement for mechanical ventilation; which may be due to the co-morbid conditions. However, this study can be an invitation for other researchers to study the effect of bubble CPAP on the survival of neonates, on duration of hospital stay in NICUs in Pakistan and thus evaluation of cost effectiveness. ${ }^{20}$ Moreover, this study can encourage researchers to study and compare various forms of CPAP as well as to modify titration and weaning protocols for use of these devices. ${ }^{21}$ While the cost of the commercial CPAP device would be decreased by using this bubble CPAP, the NICU burden in terms of increased staff requirement to care for individual neonates on DCPAP might be increased.

The contribution of neonatal mortality towards the world mortality is huge. According to UNICEF data on neonatal mortality in 2018, the neonatal mortality rate is 42 per 1000 live births in Pakistan. ${ }^{22}$ Out of these deaths, $75 \%$ of deaths occur in first week after birth. Pakistan is among the top ten countries contributing to world's neonatal mortality. ${ }^{23}$ Since all our neonatal setups are not equipped with expensive ventilation devices like CPAP, biPAP and mechanical ventilators, a major bulk of these deaths can be reduced if one can control the burden of respiratory failure by using non-invasive modalities like bubble CPAP.

\section{CONCLUSION}

Bubble CPAP has more effectiveness than nasal oxygen in treatment of respiratory distress in neonates. It should be used in the NICUs in Pakistan with limited resources, to reduce burden of neonatal morbidity due to respiratory illnesses.

\section{ETHICAL APPROVAL:}

Ethical approval was taken from Institutional Review Board of King Edward Medical University/Mayo Hospital Lahore prior to initiation of research work (Ref No. 126/RC/KEMU Dated: 05/10/2016).

\section{PATIENTS' CONSENT:}

Informed consents were taken from the parents of all patients, to publish the data concerning their cases. 


\section{CONFLICT OF INTEREST:}

Authors declared no conflict of interest.

\section{AUTHORS' CONTRIBUTION:}

TF: Principal investigator and a major contributor in data collection, analysis and interpretation, manuscript writing and literature search.

$\mathrm{MHH}$ : Co-investigator and supervisor, assisted in the selection of title, analysis and interpretation of data and final approval of manuscript.

AAJ, AW: Assisted in data collection, analysis and literature search.

\section{REFERENCES}

1. Chen A, Deshmukh AA, Richards-Kortum R, Molyneux E, Kawaza K, Cantor SB. Cost-effectiveness analysis of a low-cost bubble CPAP device in providing ventilatory support for neonates in Malawi - a preliminary report. BMC Pediatr 2014; 14:288. doi: 10.1186/s12887-014-0288-1.

2. Mustufa MA, Korejo R, Shahid A, Nasim S. Infection remains a leading cause of neonatal mortality among infants delivered at a tertiary hospital in Karachi, Pakistan. J Infect Dev Ctries 2014; 8(11):1470-5. doi: http://doi.org/ 10.3855/jidc.3569.

3. Daga S, Mhatre S, Borhade A, Khan D. Home-made continuous positive airways pressure device may reduce mortality in neonates with respiratory distress in low-resource setting. J Trop Pediatr 2014; 60(5):343-7. doi.org/10.1093/tropej/ fmu023.

4. Kawaza K, Machen HE, Brown J, Mwanza Z, Iniguez S, Gest A. Effectiveness of a low-cost bubble CPAP system in treatment of respiratory distress in a neonatal ward in Malawi. PLoS One 2014; 9(1):86327. doi.org/10.1371/ journal.pone.0086327.

5. Brown J, Machen H, Kawaza K, Mwanza Z, Iniguez S, Lang H. A high-value, low-cost bubble continuous positive airway pressure system for low-resource settings: technical assessment and initial case reports. PLoS One 2013; 8(1):e53622. doi.org/10.1371/journal.pone.0053622.

6. Stoll BJ, Hansen NI, Bell EF, Walsh MC, Carlo WA, Shankaran S, et al. Trends in Care Practices, Morbidity, and Mortality of Extremely Preterm Neonates, 1993-2012. JAMA 2015; 314(10):1039-51. doi:10.1001/jama.2015.10244.

7. Hundalani SG, Richards-Kortum R, Oden M, Kawaza K, Gest A, Molyneux $E$. Development and validation of a simple algorithm for initiation of CPAP in neonates with respiratory distress in Malawi. Arch Dis Child Fetal Neonatal Ed 2015; 100(4):332-6. doi: 10.1136/archdischild-2014-308082.

8. De Klerk AM, De Klerk RK. Nasal continuous positive airway pressure and outcomes of preterm infants. J Paediatr Child Health 2001; 37(2):161-7.

9. Kaur C, Sema A, Beri RS, Puliyel JM. A simple circuit to deliver bubbling CPAP. Indian pediatr 2008; 45(4):312-4.

10. McAdams RM, Hedstrom AB, DiBlasi RM, Mant JE, Nyonyintono J, Otai CD. Implementation of Bubble CPAP in a Rural Ugandan Neonatal ICU. Respir Care 2015; 60(3):437-45. doi.org/ 10.4187/respcare.03438.
11. Anwaar O, Hussain M, Shakeel M, Ahsan Baig MM. Outcome of use of nasal continuous positive airway pressure through infant flow drivers inneonates with respiratory distress in a teriary care hospital in Pakistan. J Ayub Med Coll Abbottabad 2018; 30(4):511-55.

12. Soomro T, Tikmani SS. Success of Bubble CPAP in treatment of respiratory distress syndrome in preterm infants. J Gen Pract (Los Angel) 2016; 4(4):264. DOI: 10.4172/ 2329-9126. 1000264.

13. Silverman WA, Andersen DH. A controlled clinical trial of effects of water mist on obstructive respiratory signs, death rate and necropsy findings among premature infants. Pediatrics 1956; 17(1):1-10.

14. Hedstrom AB, Gove NE, Mayock DE, Batra M. Performance of the Silverman Anderson Respiratory Severity Score in predicting $\mathrm{PCO} 2$ and respiratory support in newborns: A prospective cohort study. J Perinatol 2018; 38(5):505-511. doi.org/10.1038/s41372-018-0049-3.

15. Wilson PT, Morris MC, Biagas KV, Otupiri E, Moresky RT. A randomised clinical trial evaluating nasal continuous positive airway pressure for acute respiratory distress in a developing country. J Pediatr 2013; 162(5):988-92. doi: 10.1016/j.jpeds.2012.10.022.

16. Wilson PT, Baiden F, Brooks JC, Morris MC, Giessler K, Punguyire $D$, et al. Continuous positive airway pressure for children with undifferentiated respiratory distress in Ghana: an open-label, cluster, crossover trial. Lancet Glob Health 2017; 5(6):e615-e623. doi: 10.1016/ S2214-109X(17) 30145-6.

17. Al-lawama M, Alkhatib H, Wakileh Z, Elqaisi R, Al-Massad G, Badran $\mathrm{E}$, et al. Bubble CPAP therapy for neonatal respiratory distress in level III neonatal unit in Amman, Jordan: A prospective observational study. Int J Gen Med 2019; 12:25-30. doi.org/10.2147/IJGM.S185264.

18. Jasani B, Ismail A, Rao S, Patole S. Effectiveness and safety of nasal mask versus binasal prongs for providing continuous positive airway pressure in preterm infants - A systematic review and meta-analysis. Pediat Pulmonol 2018; 53(7):987-992. doi.org/10.1002/ppul.24014.

19. Ahmed Z, Shah S, Khan U, Subhani F. Use of indigenously designed bubble continuous positive airway pressure (NB-C$\mathrm{PAP}$ ) in neonates with respiratory distress- experience from a military hospital. Pak Arned Forces Med J 2016; 66(5):645-50.

20. Myhre J, Immaculate M, Okeyo B, Anand M, Omoding A, Myhre $L$, et al. Effect of treatment of premature infants with respiratory distress using low-cost bubble CPAP in a Rural African Hospital. J Trop Pediat 2016; 62(5):385-9. doi: 10. 1093/tropej/ fmw023.

21. Bhatti A, Khan J, Murki S, Sundaram V, Saini SS, Kumar P. Nasal Jet-CPAP (variable flow) versus Bubble-CPAP in preterm infants with respiratory distress: An open label, randomised controlled trial. J Perinatol 2015; 35(11): 935-40. doi: 10.1038/jp. 2015.98.

22. UNICEF. Neonatal Mortality. Available from: http://data. unicef.org/topic/child-survival/neonatal-mortality.

23. Bulletin of the World Health Organization. 2009; 87:130-8. Available from: doi: 10.2471/BLT.08.050963. 